\title{
Anxiety and depression in pregnant women amid COVID-19 pandemic
}

\author{
Pravin Shrestha ${ }^{1}$, Vibha Mahato ${ }^{2}$, Anil Subedi ${ }^{3}$, Shipra Shrestha ${ }^{4}$ \\ ${ }^{1}$ Assistant Professor, Department of Obstetrics and Gynecology, Manipal College of Medical Sciences, Pokhara, Nepal, \\ ${ }^{2}$ Lecturer, Department of Obstetrics and Gynecology, Manipal College of Medical Sciences, Pokhara, Nepal, ${ }^{3}$ Lecturer, \\ Department of Psychiatry, Manipal College of Medical Sciences, Pokhara, Nepal, ${ }^{4}$ Medical Officer, Megha Hospital, \\ Lalitpur, Nepal
}

Background: COVID-19 has become a global pandemic. It has affected the psychological condition of pregnant women. Aims and Objective: This study aims to assess prevalence of depression and anxiety in pregnancy during COVID-19 pandemic. Materials and Methods: The current study was an observational, cross sectional study conducted in the Department of Obstetrics and Gynecology, Manipal Teaching Hospital. Patients were assessed using Nepali version of Beck Anxiety Inventory (BAI) and Beck Depression Inventory (BDI) for anxiety and depression respectively. Result: There were total of 115 patients in this study. The prevalence of anxiety according to BAI was $39.1 \%$. The prevalence of depression according to BDI was $19 \%$. There was a statistically significant difference in rate of anxiety according to maternal age ( $p$ value 0.028 ). Anxiety was higher in women less than 20 years of age. Anxiety symptoms were more prevalent i.e., $44.6 \%$ in third trimester followed by $31.4 \%$ in second trimester and $29.4 \%$ in first trimester. Symptoms of depression was higher in women more than 35 years of age $(27.2 \%)$ and in second trimester of pregnancy $(27.2 \%)$. Conclusion: Antenatal anxiety and depression are important issues because it impacts both maternal wellbeing and fetal health. Prevalence of anxiety and depression among pregnant women during COVID 19 pandemic was studied. The prevalence of anxiety and depression was $39.1 \%$ and $19 \%$ respectively.

Key words: Anxiety; Depression; Pregnancy
Access this article online

Website:

http://nepjol.info/index.php/AJMS DOI: 10.3126/ajms.v12i9.37229

E-ISSN: 2091-0576

P-ISSN: 2467-9100

Copyright (c) 2021 Asian Journal of Medical Sciences

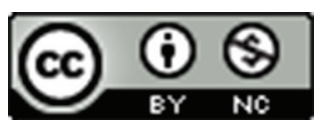

This work is licensed under a Creative Commons Attribution-NonCommercial 4.0 International License.

\section{INTRODUCTION}

The 2019 coronavirus disease (COVID-19) that first broke out in China has developed into a threat against global health, with the number of infected patients and associated deaths due to the pandemic continuing to increase. ${ }^{1}$ With its indiscriminate and sustained spread across continents, we are likely to see women with COVID-19 canvassed across all trimesters of pregnancy. ${ }^{2} \mathrm{WHO}$ classified it as a global pandemic on 11 March 2020. ${ }^{3}$ The first case in Nepal was confirmed on 23 January 2020 and each day new cases are reported. ${ }^{4}$ COVID-19 outbreak is a major public health event that has led to significant uncertainty and isolation. The negative impact may be even greater among pregnant women who have increased stress due to concerns for their fetus.
Depressive and anxiety symptoms are found to occur commonly during pregnancy in Bangladesh, drawing attention to a need to screen for depression and anxiety during antenatal care. ${ }^{5}$ Around one in every five pregnant women in Sindhupalchowk, Nepal had increased level of anxiety and nearly one in four had increased level of depression. ${ }^{6}$ The presence of psychiatric disorders during pregnancy imposes a significant burden on women and has the potential to adversely affect obstetric, fetal, and neonatal outcomes. ${ }^{7}$ Evidence from several studies have established that anxiety and depression during pregnancy are associated with preterm birth and low birth weight. ${ }^{8-10}$ A Meta-analysis done in China showed the prevalence of anxiety and depression in pregnant women during COVID-19 pandemic to be $43 \%$ and $32 \%$ respectively. ${ }^{11}$ 
Research on COVID-19 is focusing more on prevention and treatment. Research on the psychological effects of the global pandemic is deficient, especially that focusing on pregnant women. Therefore, this study aims to assess prevalence of depression and anxiety in pregnancy during COVID-19 pandemic.

\section{MATERIALS AND METHODS}

This was an observational, cross sectional study conducted in the patients attending the outpatient Department of Obstetrics and Gynecology, Manipal Teaching Hospital. The study was conducted from September 2020 to February 2021 after approval from Institutional Review Committee. Consent was taken from all patients. The questionnaire included age, place of residence, parity, gestational age, occupation, education, Obstetric history, history of psychiatric illness. Patients were enquired if COVID-19 could affect their pregnancy, their psychological health and if the social isolation has affected their psychological wellbeing. They were asked about family support. Anxiety was assessed by Beck Anxiety Inventory (BAI) and Depression was assessed by Beck Depression Inventory (BDI). All pregnant women irrespective of gestational age presenting to Department of Obstetrics and Gynecology, Manipal Teaching Hospital and consenting for the study were included. Patients with past history of psychiatric disorder were excluded from the study. Anxiety was assessed by Beck Anxiety Inventory (BAI). It is a scale developed by Aaron T, Beck and colleagues. ${ }^{12} \mathrm{BAI}$ is a commonly used self-report tool for anxiety. The BAI assesses the presence and severity of 21 symptoms over the past week. Each question is scored from 0 to 3. Nepali BAI has been validated and accordingly is a useful tool for clinical and epidemiological applications. Its sensitivity is found to be 0.77 and specificity $0.88 .^{13}$ Depression was assessed by Beck Depression Inventory (BDI).It is a scale developed by Aaron T Beck. ${ }^{14}$ The scale contains 21-item questionnaire for evaluating the severity of depression. Nepali version is available and has been validated. Its sensitivity is 0.73 and specificity $0.91 .{ }^{15}$ The data obtained was recorded in a proforma and in excel sheet. Statistical Package for the social sciences version 16 was used for calculation and tabulation of data. Level of significance was set as 0.05 . The final results were discussed comparing with results in other studies and the conclusion was derived.

\section{Sample size}

Sample size calculation was done by standard formula where $\mathrm{p}$ is prevalence, $\mathrm{q}$ is $1-\mathrm{p}$, $\mathrm{e}$ is margin of error, $\mathrm{Z}=1.96$ at $95 \%$ CI. ${ }^{16}$ Data was collected by census sampling method. According to the study done in Sindhupalchowk, Nepal,
$21.3 \%$ of pregnant women had anxiety and $23.8 \%$ had depression. ${ }^{6}$ At $95 \%$ confidence interval,

$$
\begin{aligned}
& \mathrm{p}=23.8 \% \mathrm{q}=100-\mathrm{p}=76.2 \text { Margin of error } \\
& \mathrm{e}=\sqrt{\left(4 * p^{*}(1-p) / 100\right.} \mathrm{e}=0.084 \mathrm{n}=\mathrm{Z}^{2} \times \mathrm{p} \times \mathrm{q} / \mathrm{e}^{2} \\
& \mathrm{n}=(1.96)^{2} * 0.238 * 0.762 /(0.08)^{2} \text { Sample size }=109
\end{aligned}
$$

\section{RESULT}

The study included a total of 115 patients. The mean age of patients was $26+4.98$ years (16-40years). Majority of patients i.e., $61(53 \%)$ were primigravida while 54(47\%) were multigravida. Seventeen $(14.7 \%)$ patients were in first trimester, 33(28.6\%) in second trimester and 65(56.5\%) in third trimester. Twenty-one $(18.2 \%)$ women were from rural area and $94(81.7 \%)$ from urban area. Majority of them, $65(56.5 \%)$ thought COVID-19 can affect their pregnancy, $42(36.5 \%)$ thought it can affect their psychological health, only $34(29.5 \%)$ said social isolation has affected their psychological wellbeing. Majority of patients, 106 (92.1\%) had family support. Severity of anxiety according to BAI was assessed. The prevalence of anxiety according to BAI was $39.1 \%$. Mild anxiety was found in 33(28.6\%) followed by moderate in $11(9.6 \%)$ and severe in $1(0.9 \%)$. The prevalence of depression according to BDI was $19 \%$. Severity of depression according to BDI showed mild mood disturbance in 20(17.4\%), borderline clinical depression in $2(1.7 \%)$. There were no patients of moderate, severe or extreme depression.

Anxiety was higher in women less than 20 years of age $(55.5 \%)$. Homemakers had a higher rate of anxiety $(43.2 \%)$ as compared to others. Anxiety symptoms was found to be more in third trimester (44.6\%) followed by 31.4\% in second trimester and $29.4 \%$ in first trimester. Symptoms of depression were higher in women more than 35 years of age $(27.2 \%)$ and in second trimester of pregnancy $(27.2 \%)$ as shown in Table 1.

A statistically significant association with anxiety and depression was found among women with history of subfertility and those with pregnancy complication, both past and present as shown in Table 2.

Multiple regression was performed keeping BAI, BDI as dependent variable and BMI, partner support, parity and literacy as independent variables. Our analysis showed that lack of partner support was significantly associated with anxiety and it had positive correlations. There were no significant associations between BMI, parity or literacy with either depression or anxiety as shown in Table 3.

This study included total of 115 pregnant women attending antenatal clinic of Manipal Teaching Hospital. 


\begin{tabular}{|c|c|c|c|c|c|}
\hline Characteristics & $\mathbf{N}$ & $\begin{array}{c}\text { Anxiety } \\
\text { (n \%) }\end{array}$ & $p$ value & $\begin{array}{l}\text { Depression } \\
(\mathrm{n} \%)\end{array}$ & $p$ value \\
\hline \multicolumn{6}{|l|}{ Age } \\
\hline$<20$ & 9 & $5(55.5)$ & 0.278 & 0 & 0.266 \\
\hline $20-35$ & 95 & $34(35.7)$ & & $19(20)$ & \\
\hline$>35$ & 11 & 6(54.5) & & $3(27.2)$ & \\
\hline \multicolumn{6}{|l|}{ Occupation } \\
\hline Homemaker & 81 & $35(43.2)$ & & $15(18.5)$ & \\
\hline Others & 34 & $10(29.4)$ & 0.122 & $7(20.5)$ & 0.567 \\
\hline \multicolumn{6}{|l|}{ Weeks of gestation } \\
\hline $1^{\text {st }}$ trimester & 17 & $5(29.4)$ & 0.375 & $1(5.88)$ & 0.186 \\
\hline $2^{\text {nd }}$ trimester & 33 & $11(31.4)$ & & $9(27.2)$ & \\
\hline $3^{\text {rd }}$ trimester & 65 & $29(44.6)$ & & $12(18.4)$ & \\
\hline
\end{tabular}

\begin{tabular}{|c|c|c|c|c|c|c|}
\hline Risk factors & $\begin{array}{l}\text { Anxiety } \\
\text { (p value) }\end{array}$ & $\begin{array}{l}\text { Odd's } \\
\text { ratio }\end{array}$ & $\begin{array}{c}95 \% \\
\mathrm{Cl}\end{array}$ & $\begin{array}{c}\text { Depression } \\
\text { (p value) }\end{array}$ & $\begin{array}{l}\text { Odd's } \\
\text { ratio }\end{array}$ & $\begin{array}{c}95 \% \\
\mathrm{Cl}\end{array}$ \\
\hline $\begin{array}{l}\text { History of } \\
\text { subfertility }\end{array}$ & .009 & 10.62 & $\begin{array}{l}1.23- \\
91.4\end{array}$ & .036 & 3.51 & $\begin{array}{c}0.73- \\
17\end{array}$ \\
\hline $\begin{array}{l}\text { Past } \\
\text { pregnancy } \\
\text { complications }\end{array}$ & .004 & 17 & $\begin{array}{l}3.66- \\
79.03\end{array}$ & .036 & 2.8 & $\begin{array}{l}0.9- \\
8.65\end{array}$ \\
\hline $\begin{array}{l}\text { Past } \\
\text { morbidities }\end{array}$ & .051 & 1.48 & $\begin{array}{l}0.72- \\
3.15\end{array}$ & .304 & 1.28 & $\begin{array}{l}0.5- \\
3.25\end{array}$ \\
\hline $\begin{array}{l}\text { Present } \\
\text { pregnancy } \\
\text { complications }\end{array}$ & $<.001$ & 9.71 & $\begin{array}{l}2.02- \\
46.79\end{array}$ & .002 & 8.21 & $\begin{array}{l}2.3- \\
29.2\end{array}$ \\
\hline
\end{tabular}

The prevalence of anxiety according to BAI was $39.1 \%$. Before the pandemic, study done in Bangladesh by Nasreen HE et al., found rates of antenatal anxiety to be $29 \%{ }^{5}$ The prevalence of anxiety was $21.3 \%$ in a study done in Sindupalchowk, Nepal by Aryal KK et al. ${ }^{6}$ Prevalence of anxiety in a Meta-analysis done in China was 43\% during COVID-19 pandemic. ${ }^{11}$ The prevalence of anxiety was higher during this pandemic in our study as compared to the study done in Nepal before the pandemic. Uncertainty about the duration of the COVID-19 pandemic increases the anxiety level of pregnant women. ${ }^{17}$ Anxiety was higher in women less than 20 years of age (55.5\%), which was similar to the study done by Bodecs et al., which identified young age as a risk factor for anxiety. ${ }^{18}$ Homemakers had higher rates of anxiety (43.2\%) as compared to employed women in our study similar to the study done by Alqahtani $\mathrm{AH} .{ }^{19}$ Anxiety symptoms were more in $3^{\text {rd }}$ trimester $(44.6 \%)$ followed by $2^{\text {nd }}$ trimester $(31.4 \%)$ and $1^{\text {st }}$ trimester $(29.4 \%)$ similar to the study done by Dennis $\mathrm{CL}^{20}$ where anxiety symptoms were $4.6 \%, 19.1 \%$ and $18.2 \%$ respectively in third, second and first trimester of pregnancy. It may be because women are more vulnerable as they are nearer to delivery date and are anxious about starting a new phase of their lives.

Majority of our patients, 65 (56.5\%) thought COVID 19 can affect their pregnancy. In the study done by Durankus

\section{Table 3: Correlated for Anxiety and depression}

\begin{tabular}{|c|c|c|c|c|c|c|c|c|}
\hline & \multicolumn{4}{|c|}{ Anxiety } & \multicolumn{4}{|c|}{ Depression } \\
\hline & B & S. E & $t$ & Sig & B & S. E & $\mathbf{t}$ & Sig \\
\hline BMI & 0.014 & 0.089 & 0.161 & 0.873 & 0.065 & 0.074 & 0.883 & 0.379 \\
\hline $\begin{array}{l}\text { Lack of } \\
\text { partner } \\
\text { support }\end{array}$ & 0.253 & 0.093 & 2.728 & 0.007 & 0.016 & 0.076 & 2.06 & 0.08 \\
\hline Parity & 0.080 & 0.096 & 0.082 & 0.405 & 0.012 & 0.079 & 0.155 & 0.877 \\
\hline Literacy & 0.000 & 0.177 & -0.006 & 0.996 & 0.226 & 0.146 & 1.54 & 0.124 \\
\hline
\end{tabular}

F., ${ }^{21} 76.2 \%$ of women thought it could affect the pregnancy process.

The prevalence of depression in this study according to BDI was $19.1 \%$ which was similar (18\%) to the study done by Nasreen HE. ${ }^{5}$ In a study done by Aryal KK, $23.8 \%$ had depression. ${ }^{6}$ Depression in pregnant women during COVID-19 pandemic was found to be $32 \%$ in a study done in China. ${ }^{11}$ There was no increase in depression during the pandemic in our study. It may be because women are reluctant to share symptoms of depression due to social taboos and may require a greater number of visits. Symptoms of depression were higher $(27.2 \%)$ in women more than 35 years of age. Increasing age was found as a factor associated with depression in a study done by Ali NS. ${ }^{22}$ Depression was found to be higher in second trimester of pregnancy $(27.2 \%)$ followed by $18.4 \%$ in third trimester and $5.88 \%$ in first trimester. Similarly, prevalence rate was higher i.e., $12.8 \%$ in second trimester followed by $12 \%$ and $7.4 \%$ in third and first trimester respectively in the study done by Bennet HA. ${ }^{23} \mathrm{~A}$ study done by Durankus F suggested that psychosocial support is required to this population during this pandemic to prevent adverse effects to both mother and fetus. ${ }^{21}$

The impact of subfertility on psychological wellbeing of couples is a growing concern. In our study, women with history of subfertility had positive association with anxiety and depression. A study done by Ramezanzadeh et al showed $40.8 \%$ depression and $86.8 \%$ anxiety in infertile women. ${ }^{24}$ Women with current or past pregnancy/delivery complications, with a history of pregnancy loss, pregnancy terminations or stillbirth have been found to be more likely to experience antenatal anxiety, depression. ${ }^{25}$ In the study done by Jing Chen et al anxiety and depression symptoms were more common in pregnant women with a history of previous complications or current pregnancy complications similar to our study. ${ }^{26}$ There were no significant associations between BMI and depression or anxiety in our study similar to the study done by Insan $\mathrm{N}$ et al., where no association was found in South Asian women while British women with an overweight BMI had higher odds of anxiety. ${ }^{27}$ 
Lack of partner support is associated with an increased risk of antenatal anxiety. ${ }^{28}$ Our analysis showed lack of partner support associated with anxiety ( $p$ value 0.007 ) with positive correlations. Our study did not find any significant association between parity and antenatal mental health similar to the study done by Abujiban S.K et al. ${ }^{29}$ Our study did not find education to be a predictor of antenatal anxiety and depression similar to the study done by Agostini F et al..$^{30}$

\section{CONCLUSION}

This study examined mental health of pregnant women during COVID-19 pandemic. Majority of the women thought COVID-19 could affect their pregnancy. The prevalence of anxiety and depression was $39.1 \%$ and $19 \%$ respectively. Proper screening and diagnosis would bring early treatment to needy thus preventing complication to both the mother and the newborn.

\section{REFERENCES}

1. Wang C, Horby PW, Hayden FG and Gao GF. A novel coronavirus outbreak of global health concern. The Lancet. 2020;395(10223):470-473

https://doi.org/10.1016/S0140-6736(20)30185-9

2. Dashraath P, Wong JLJ, Lim MXK, Lim LM, Li S, Biswas A, et al. Coronavirus disease 2019 (COVID-19) pandemic and pregnancy. Am J Obstet Gynecol. 2020; 222(6):521-531. https://doi.org/10.1016/j.ajog.2020.03.021

3. Cucinotta D and Vanelli M. WHO declares COVID-19 a pandemic. Acta bio-medica: Atenei Parmensis. 2020; 91(1): 157-160.

4. Shrestha R, Shrestha S, Khanal P and Bhuvan KC. Nepal's first case of COVID-19 and public health response. Journal of travel medicine. 2020;27(3): taaa024.

https://doi.org/10.1093/jtm/taaa024

5. Nasreen HE, Kabir ZN, Forsell $Y$ and Edhborg M. Prevalence and associated factors of depressive and anxiety symptoms during pregnancy: a population-based study in rural Bangladesh. BMC women's health. 2011;11(1):1-9.

https://doi.org/10.1186/1472-6874-11-22

6. Aryal KK, Alvik A, Thapa N, Mehata S, Roka T, Thapa P, et al. Anxiety and Depression among Pregnant Women and Mothers of Children Under one Year in Sindupalchowk District. Journal of Nepal Health Research Council. 2018;3(16):195-204

https://doi.org/10.33314/jnhrc.v16i2.1219

7. Woody CA, Ferrari AJ, Siskind DJ, Whiteford HA and Harris MG. A systematic review and meta-regression of the prevalence and incidence of perinatal depression. Journal of affective disorders. 2017; 219:86-92.

https://doi.org/10.1016/j.jad.2017.05.003

8. Alder J, Fink N, Bitzer J, Hösli I and Holzgreve W. Depression and anxiety during pregnancy: a risk factor for obstetric, fetal and neonatal outcome? A critical review of the literature. The Journal of Maternal-Fetal and Neonatal Medicine. 2007;20(3):189-209. https://doi.org/10.1080/14767050701209560

9. Schetter CD, Tanner L. Anxiety, depression and stress in pregnancy: implications for mothers, children, research, and practice. Current opinion in psychiatry. 2012 Mar; 25(2):141. Doi:10.1097/YCO.0b013e3283503680.

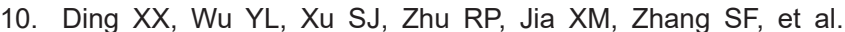
Maternal anxiety during pregnancy and adverse birth outcomes: a systematic review and meta-analysis of prospective cohort studies. Journal of affective disorders. 2014; 159:103-110. https://doi.org/10.1016/j.jad.2014.02.027

11. Zhang J, Yu H, Gao Y, Xu Q, Yin Y and Zhou R. Prevalence of anxiety and depression among pregnant women during the COVID-19 pandemic: a systematic review and metaanalysis.2020. https://doi.org/10.21203/rs.3.rs-87129/v1

12. Beck AT, Epstein N, Brown $G$ and Steer RA. An inventory for measuring anxiety: Psychometric properties. Journal of Consulting and Clinical Psychology. 1988; 56:893-897. https://doi.org/10.1037//0022-006x.56.6.893

13. Kohrt BA, Kunz RD and Koirala NR. Validation of the Nepali version of beck anxiety inventory. Journal of Institute of Medicine. 2007; 26 (3).

14. Beck AT, Ward $\mathrm{CH}$, Mendelson $\mathrm{M}$, Mock $\mathrm{J}$ and Erbaugh $\mathrm{J}$. An inventory for measuring depression. Archives of general psychiatry. 1961;4(6):561-571.

https://psycnet.apa.org/doi/10.1001/archpsyc. 1961.01710120031004

15. Kohrt BA, Kunz RD, Koirala NR, Sharma VD and Nepal MK. Validation of a Nepali version of the Beck Depression Inventory. Nepalese Journal of Psychiatry. 2002; 2 (4):123-130.

16. Sathian B, Sreedharan J, Banerjee I and Roy B. Simple sample size calculator for medical research: a necessary tool for the researchers. Medical Science. 2014;2(3):141-144. https://doi.org/10.29387/ms.2014.2.3.141-144

17. Taubman-Ben-Ari O, Chasson M, Abu Sharkia S and Weiss E. Distress and anxiety associated with COVID-19 among Jewish and Arab pregnant women in Israel. Journal of reproductive and Infantpsychology.2020;38(3):340-348.

https://doi.org/10.1080/02646838.2020.1786037

18. Bödecs T, Szilágyi E, Cholnoky P, Sándor J, Gonda X, Rihmer Z, et al. Prevalence and psychosocial background of anxiety and depression emerging during the first trimester of pregnancy: data from a Hungarian population-based sample. Psychiatria Danubina. 2013;25(4):0-358.

19. Alqahtani $\mathrm{AH}, \mathrm{Al}$ Khedair $\mathrm{K}, \mathrm{Al}-J e h e i m a n \mathrm{R}, \mathrm{Al}$-Turki $\mathrm{HA}$ and $\mathrm{Al}$ Qahtani NH. Anxiety and depression during pregnancy in women attending clinics in a University Hospital in Eastern province of Saudi Arabia: prevalence and associated factors. International journal of women's health. 2018; 10:101 https://dx.doi.org/10.2147\%2FIJWH.S153273

20. Dennis CL, Falah-Hassani $\mathrm{K}$ and Shiri R. Prevalence of antenatal and postnatal anxiety: systematic review and metaanalysis. The British Journal of Psychiatry. 2017; 210(5):31523. https://doi.org/10.1192/bjp.bp.116.187179

21. Durankuş $F$ and Aksu E. Effects of the COVID-19 pandemic on anxiety and depressive symptoms in pregnant women: a preliminary study. The Journal of Maternal-Fetal and Neonatal Medicine. 2020;1-7. https://doi.org/10.1080/14767058.2020.1763946

22. Ali NS, Azam IS, Ali BS, Tabbusum G and Moin SS. Frequency and associated factors for anxiety and depression in pregnant women: a hospital-based cross-sectional study. The Scientific World Journal. 2012 Oct; 2012. https://doi.org/10.1100/2012/653098

23. Bennett HA, Einarson A, Taddio A, Koren G, Einarson TR. Prevalence of depression during pregnancy: systematic review. Obstetrics and Gynecology. 2004;103(4):698-709. 
https://doi.org/10.1097/01.aog.0000116689.75396.5f

24. Ramezanzadeh F, Aghssa MM, Abedinia N, Zayeri $F$, Khanafshar N, Shariat M, et al. A survey of relationship between anxiety, depression and duration of infertility. BMC women's health. 2004;4(1):1-7.

https://doi.org/10.1186/1472-6874-4-9

25. Fisher J, Tran T, Tran TD, Dwyer T, Nguyen T, Casey GJ, et al. Prevalence and risk factors for symptoms of common mental disorders in early and late pregnancy in Vietnamese women: a prospective population-based study. Journal of affective disorders. 2013;146(2):213-219.

https://doi.org/10.1016/j.jad.2012.09.007

26. Chen J, Cai Y, Liu Y, Qian J, Ling Q, Zhang W, et al. Factors associated with significant anxiety and depressive symptoms in pregnant women with a history of complications. Shanghai archives of psychiatry. 2016;28(5):253.

https://doi.org/10.11919/j.issn.1002-0829.216035]

27. Insan N, Slack E, Heslehurst $\mathrm{N}$ and Rankin J. Antenatal depression and anxiety and early pregnancy BMI among White
British and South Asian women: retrospective analysis of data from the Born in Bradford cohort. BMC pregnancy and childbirth. 2020;20(1):1-1.

https://doi.org/10.1186/s12884-020-03097-2

28. Bayrampour $\mathrm{H}, \mathrm{McD}$ onald $\mathrm{S}$ and Tough $\mathrm{S}$. Risk factors of transient and persistent anxiety during pregnancy. Midwifery. 2015;31(6):582-589.

https://doi.org/10.1016/j.midw.2015.02.009

29. Abujilban SK, Abuidhail J, Al-Modallal H, Hamaideh S and Mosemli O. Predictors of antenatal depression among Jordanian pregnant women in their third trimester. Health care for women international. 2014;35(2):200-215.

https://doi.org/10.1080/07399332.2013.817411

30. Agostini F, Neri E, Salvatori P, Dellabartola $S$, Bozicevic $L$ and Monti F. Antenatal depressive symptoms associated with specific life events and sources of social support among Italian women. Maternal and Child Health Journal. 2015;19(5):1131-1141. https://doi.org/10.1007/s10995-014-1613-x

\section{Author's Contribution:}

PS - Concept and design of the study; prepared first draft of manuscript, interpreted the results; reviewed the literature and manuscript preparation; VM - Concept, coordination, review of literature and manuscript preparation; AS - Concept, Statistical analysis and interpretation; SS - Preparation of manuscript, revision of the manuscript and statistical analysis.

Work Attributed to:

Manipal College of Medical Sciences, Phulbari, Pokhara, Nepal.

Orcid ID:

Dr. Pravin Shrestha - (1) https://orcid.org/0000-0002-4767-9407

Dr. Vibha Mahato - (1) https://orcid.org/0000-0002-5116-0405

Dr. Anil Subedi - (1) https://orcid.org/0000-0001-8191-993X

Dr. Shipra Shrestha - (1) https://orcid.org/0000-0001-7642-7949

Source of Funding: None, Conflict of Interest: None. 